\title{
Los convenios de asociación con entidades sin ánimo de lucro: falencias en su aplicación y perspectivas hacia la eficiencia de la inversión social ${ }^{*}$
}

\author{
Partnership agreements with non-profit entities: Weaknesses \\ in their application and perspectives towards the efficiency of social investment
}

\section{RESUMEN}

Las falencias en la aplicación de la figura jurídica de los convenios de asociación bajo la normatividad de los decretos 777 y 1403 de 1992, evidenciadas a través del análisis teóricopráctico, mostraron un impacto negativo en la aplicación de los convenios. Ello evidenció la necesidad de una nueva reglamentación que, de manera real y efectiva, armonizara esta tipología con el Estatuto General de la Contratación Pública y la aplicación de los principios

\footnotetext{
Este artículo es producto del proyecto de investigación "Los convenios de asociación con entidades sin ánimo de lucro desde un enfoque equitativo, eficiente y eficaz de los recursos públicos", gestionado en el marco de la Maestría en Derecho Administrativo de la Universidad Libre (Bogotá, Colombia).

Citar como: Acosta Suárez, N. y Guarnizo Rojas, M. L. (2020). Los convenios de asociación con entidades sin ánimo de lucro: falencias en su aplicación y perspectivas hacia la eficiencia de la inversión social. Via Inveniendi et Iudicandi, 15(1), 219-245. DoI: https://doi.org/10.15332/19090528/5748

** Magíster en Derecho Administrativo de la Universidad Libre (Bogotá, Colombia) y especialista en Derecho constitucional de la misma universidad, Abogada con formación y experiencia en derecho disciplinario, administrativo, civil, procesal, contratación pública y derechos humanos. Correo electrónico: neas40@hotmail. com. ORCID: https://orcid.org/0000-0002-4424-6980.

*** Abogada, magíster en Derecho Administrativo y especialista en Derecho Procesal e Instituciones Jurídico-políticas y de Derecho Público: conciliadora en derecho con formación en derechos humanos, contratación pública y resolución de conflictos urbanos, con énfasis en el campo disciplinario y en la gestión de procesos contractuales. Correo electrónico: marthalguarnizo@hotmail.com. oRCID: https://orcid.org/0000-0001-6492-7487.
} 
que la rigen, en especial los de transparencia y selección objetiva, desconocidos y violentados de manera reiterada con el uso indebido y exagerado de esta figura exceptiva, a fin de obviar mecanismos de selección contemplados en la ley contractual.

A pesar de que el Decreto 092 del 2017 consagró la aplicación de los principios de la contratación estatal a los convenios de asociación con entidades sin ánimo de lucro, no determinó criterios objetivos que permitieran garantizar la selección objetiva de una ESAL y, mucho menos, integrarla de manera efectiva al estatuto contractual.

La pregunta problematizadora de este manuscrito es ¿cómo superar las falencias en la aplicación de los convenios de asociación para garantizar la eficiencia en la inversión social de los recursos públicos? Los objetivos específicos del artículo son: determinar los antecedentes históricos y normativos de los convenios de asociación; demostrar las falencias en la aplicación de la figura jurídica evidenciadas en el estudio de cinco procesos disciplinarios de convenios de asociación, a la luz de los decretos 777 y 1403 de 1992, y proponer la inclusión de los convenios de asociación como una modalidad de la contratación estatal para garantizar la aplicación de los principios de transparencia y selección objetiva.

Palabras claves: falencias, convenios de asociación, entidades sin ánimo de lucro, principios de transparencia y selección objetiva y criterios objetivos.

\section{Abstract}

The shortcomings in the application of the legal figure of the partnership agreements under the regulations of decrees 777 and 1403 of 1992, evidenced through the theoretical-practical analysis, showed a negative impact on the application of the agreements. It evidenced the need for a new regulation that, in a real and effective way, will harmonize this typology with the General Statute of Public Procurement and the application of the principles that govern it, especially those of transparency and objective selection, unknown and violated in a repeated way with the improper and exaggerated use of this exceptive figure, in order to obviate the selection of mechanisms contemplated in the contractual law. 
Despite the promulgation of Decree 092 of 2017 enshrined the application of the principles of state contracting to partnership agreements with non-profit entities, it did not determine objective criteria that would guarantee the objective selection of the non-profit organizations (NPO) and, much less, its effective integration into the contractual statute.

The problematic question of this manuscript is: how to overcome the shortcomings in the application of partnership agreements to ensure the efficiency in social investment of public resources? The specific objectives of the article are to determine the historical and normative antecedents of the partnership agreements; demonstrate the flaws in the application of the legal figure evidenced in the study of five disciplinary partnership agreements, in light of decrees 777 and 1403 of 1992, and propose the inclusion of the partnership agreements as a modality of state contracting to guarantee the application of the principles of transparency and objective selection.

Keywords: flaws, partnership agreements, non-profit organizations, principles of transparency and objective selection and objective criteria. 


\section{INTRODUCCIÓN}

El Estado social de derecho orienta sus fines esenciales, en principio, a servir a la comunidad y a promover la prosperidad general, lo que se concreta a través de la función pública y, en especial, de la gestión contractual. Se constituye así, la actividad de fomento del Estado como mecanismo eficaz para materializar los fines enunciados mediante la financiación de las entidades sin ánimo de lucro con el fin de incentivar e impulsar el cumplimiento de su misión. Esto no es otra que realizar obras benéficas en procura de satisfacer especialmente las necesidades de la población en condiciones de vulnerabilidad (Blanco, 2013).

Siendo esta una tarea esencial del Estado, la colaboración que prestan las entidades del tercer sector -empresas privadas sin ánimo de lucro- se torna vital, en razón de que su misión tiene como componente el fin social y que su actividad genera cohesión, solidaridad y conciencia ciudadana; de ahí la necesidad de que el Estado destine parte del presupuesto de inversión social a incentivar, fomentar y promover la acción benéfica de esa especial categoría de particulares (Saidiza y Carvajal, 2016)

Bajo este contexto y frente a la mirada histórica sobre la aplicación de fomento del Estado que no ha logrado cumplir el loable cometido que la orienta (Palomares y Calonje, 2015) es como surge la necesidad de una normativa que garantice la efectividad de los principios de contratación estatal aplicados en la escogencia de las ESAL, con criterios objetivos que excluyan todo factor de afecto o interés (Millán, Blanco y Guecha, 2017). Por el contrario, dicha actividad de fomento ha quedado permeada por la corrupción y los excesos de quienes administran el presupuesto público con intereses particulares y mezquinos y no según el interés general, todo lo cual desvía la inversión social y, con ello, evita que se forje y construya el progreso y el avance significativo que impulse el desarrollo integral de la ciudadanía en general.

La metodología investigativa que orientó el desarrollo del presente trabajo fue la de estudio cualitativo con enfoque jurídico de la información referente al tema. Se aplicó el método teórico deductivo a través del análisis y síntesis del material documental, desde fuentes primarias y secundarias, teniendo presente el referente normativo constitucional, legal y reglamentario. Este se integró con la jurisprudencia de la Corte Constitucional y del Consejo de Estado, así como la amplia doctrina, 
artículos científicos publicados en revistas indexadas y trabajos de tesis que abordaron el tema desde diferentes ópticas y que permitieron reafirmar el enfoque y la propuesta delineada en el trabajo investigativo.

Lo anterior se complementó con el estudio y análisis de cinco casos escogidos, como una manera de evidenciar las falencias en la aplicación de los convenios de asociación con entidades privadas sin ánimo de lucro, conocidos previamente durante la experiencia laboral como operadores disciplinarios en el organismo de control distrital, Personería de Bogotá.

\section{MARCO HISTÓRICO Y NORMATIVO DE LOS CONVENIOS DE ASOCIACIÓN CON ENTIDADES PRIVADAS SIN ÁNIMO DE LUCRO}

Resulta académicamente apropiado abordar el marco normativo de los convenios de asociación dentro de tres tópicos o perspectivas: el primero corresponde a los antecedentes históricos en el Estado colombiano desde finales del siglo XIX, empezando con la promulgación de la Constitución Política de 1886. Esta carta constitucional emerge con una estabilidad de más de un siglo dentro del proceso de conformación del Estado república que vivió nuestra nación, en el vaivén de los regímenes centralistas y federalistas (Henao Hidrón, 1992). Así se impuso, finalmente, a través de las guerras internas, un Estado centralista presidencialista que nos definió y que ha sido el contexto político democrático en que se ha desarrollado el Estado y se ha consolidado la cultura constitucional colombiana (Tirado, Bedoya y Blanco, 2016).

Lo anterior pone en contexto la actividad estatal de fomento o impulso a entidades particulares benefactoras o solidarias que colaboran con el Estado en la atención de servicios de interés común y en favor de los asociados cuyo origen normativo se remonta a la Constitución de 1886. Es este un mecanismo idóneo que incentivó la participación de los particulares en la ejecución de las actividades públicas inherentes al Estado, pero que, por el abuso que las autoridades públicas le dieron, se convirtió en el núcleo central que desbordó la corrupción. Esto motivó el cambio constitucional promovido por la Asamblea Nacional Constituyente que finalmente promulgó la Constitución de 1991 que aún nos rige (Blanco y Gómez, 2016). 
El segundo tópico corresponde a la evolución normativa de los convenios de asociación, desde su creación con la Constitución de 1991 y los decretos reglamentarios que desarrollaron la figura jurídica, y como tercer tópico abordaremos las falencias de la aplicación de los convenios de asociación bajo la vigencia de los decretos reglamentarios Nos. 777 y 1403 de 1992.

\section{Antecedentes históricos}

Fue la Constitución Política de 1886 la que consagró dentro del ámbito de competencias del Congreso de la República, en su artículo 76, numeral 18, el fomento de "empresas útiles y benéficas, dignas de estímulo o apoyo". Se instituye con ello el incentivo como una forma de financiación por parte del Estado a empresas particulares cuyo objeto social está encausado a prestar un servicio a la comunidad, sin contraprestación alguna ni interés lucrativo; tan solo con fines benéficos y de solidaridad, coadyuvando a satisfacer necesidades de interés comunitario, propias de la gestión estatal (C. Constitucional C 372/1994, M. P. V. Naranjo).

Después, con la reforma constitucional de 1945, (Acto Legislativo 1 de 1945) al modificar el artículo 69, de las atribuciones del Congreso, estipuló en su numeral 4. ${ }^{\circ}$ : "Fijar los planes y programas a que debe someterse el fomento de la economía nacional, y los planes y programas de todas las obras públicas que hayan de emprenderse o continuarse", lo que determinó que la actividad de fomento atribuida al Congreso, así como el gasto público en general, se sujetaran a planes y programas que diseñara esta corporación, integrando en el manejo presupuestal una verdadera planeación (Guarín y Aldana, 2016; González, 2014).

Continúa la evolución de la figura jurídica que nos convoca con la reforma constitucional de 1968 (Acto Legislativo 1 de 1968), en la que se amplió la facultad de fomento, en cabeza del Congreso de la República, a las asambleas y los concejos, con el fin de que se destinaran recursos para atender necesidades directas de las comunidades locales (Sänger, 2015; Gallego, 2014), aprovechando el especial interés y mayor contacto, dado que, por estar alejadas del centro de poder, pasaban inadvertidas en los planes de inversión estatal. Así, inicialmente se cumplió el objetivo plausible con el que se adoptó esta práctica política, y las cuotas que cada uno de los 
congresistas recibía se invertían en sus respectivas circunscripciones electorales para impulsar empresas útiles o benéficas (Barragán, 2016).

Es importante resaltar que, si bien se extendió la actividad de fomento a las corporaciones públicas del nivel local en todo el territorio nacional con esta reforma constitucional, al Congreso se le suprimió la facultad de planificación del gasto público, a través de la fijación de los planes y programas para el manejo del presupuesto y se reservó en el ejecutivo esta potestad, que marca el énfasis del poder de la figura presidencial, distintivo en el sistema presidencialista clásico que impera en nuestra república (Garzón, 2013)

Esta reforma les restó a los congresistas las atribuciones que hasta entonces detentaban en materia de intervención en la economía, a cambio de autorizar atribuciones exclusivas al ejecutivo en materia de hacienda pública, dado que reservó en forma exclusiva para el gobierno la iniciativa de los proyectos de ley sobre el gasto público. Les dejó así a los congresistas, como contrapartida por la pérdida de competencia y a título de excepción, la libre iniciativa en los proyectos atinentes al fomento "de las empresas útiles o benéficas dignas de estímulo o apoyo, con estricta sujeción a los planes y programas correspondientes", según los términos del ordinal 20 del artículo 76 superior (Cortés, 2016; Pardo, 2014)

La Corte Constitucional, en la sentencia en cita, continúa manifestando que no puede desconocerse que el espíritu descentralizado de la reforma de 1968 tuvo aciertos y aplicación que favoreció a las comunidades locales; sin embargo, bien pronto prácticas politiqueras empezaron a desvirtuar el fin para el cual fue concebida la norma comentada, generando una distorsión de tal magnitud que vino a constituirse en una de las mayores fuentes de corrupción, desprestigio y envilecimiento de la función legislativa (Rodríguez, 2014).

Bajo estas premisas, se creó una cantidad exagerada de corporaciones o fundaciones privadas hacia las cuales se desviaron los recursos (Humbarita, 2015). Se incrementaron, entonces, las actividades de fomento y estímulo como mecanismo para conceder favores y obtener a cambio la conservación o el aumento de clientelas políticas, lo que condujo, entre otras cosas, a favorecer desequilibrios regionales derivados de la diferente proporción en que cada región estaba representada, sin contar las ocasiones en que el poder ejecutivo se reservaba una parte que luego repartía 
entre algunos congresistas, particularmente entre los integrantes de las comisiones de presupuesto de una y otra cámara (Patarroyo y Benavides, 2014)

Resulta paradójico que, con el auge de la planeación y la racionalización del gasto público, se aumentaran las partidas decretadas con base en la actividad de impulso y fomento, a punto de llegar a comprometer grandes cantidades de dinero que, por esa vía, se deslizaban hacia el patrimonio personal del congresista o hacia la financiación de campańas electorales, con lo que se evidenciaba una ausencia de adecuados y efectivos mecanismos de control sobre la destinación e inversión de esos recursos.

Aunado a lo anterior, se acrecentó y desbordó esta práctica patológica, por cuanto las actuaciones irregulares y distorsionadas que se presentaron en el nivel central se replicaron en el ámbito territorial. Esto finalmente determinó el rechazo explícito de esas prácticas corruptas que deformaron la imagen del Congreso y sembraron en la ciudadanía la desconfianza hacia la corporación legislativa y la impresión sobre su ilegitimidad. Se constituyó así como piedra angular para que la Asamblea Nacional se erigiera como una ventana de oportunidad política (Jiménez y Soler Pedroza, 2013) para expedir la Carta Constitucional de 1991, con la modernización y la concepción del Estado social democrático y constitucional de derecho bajo una consigna de anticorrupción, reflejada en el clamor ciudadano para eliminar esa práctica nociva que se acuñó con la denominación de auxilios parlamentarios (Cortés, 2013; Rodríguez, 2016)

Las anteriores consideraciones demuestran y justifican la contundente prohibición que contiene el artículo 355 de la Constitución de 1991, que, por lo demás, responde a un propósito loable de indudable carácter corrector de situaciones anómalas que se busca suprimir definitivamente, según lo expresó el magistrado Vladimiro Naranjo Mesa en la sentencia C 372 de 1994.

\section{Desarrollo normativo de los convenios}

\section{de asociación con entidades privadas sin ánimo de lucro}

El régimen normativo de los convenios de asociación con entidades privadas sin ánimo de lucro actualmente se encuentra consagrado en la Constitución Política de 
1991, en el Artículo 355², reglamentado por los decretos 777, 1403 de 1992 y 2459 de 1993, derogados hace poco por el Decreto 092 del 2017 (27 de enero), cuya vigencia empieza el $1 .^{\circ}$ de junio de esa anualidad.

Los convenios de asociación tienen una normatividad especial, anterior y ajena al estatuto contractual colombiano, y nacieron como una forma de eliminar los llamados auxilios parlamentarios ya mencionados.

La prohibición contenida en el artículo 355 de la Carta se activará cuando el auxilio, subsidio o incentivo o donación, cualquiera que sea su origen, se reconozca por mera liberalidad como una simple transferencia de recursos y no con criterio redistributivo. De este modo, se convierte en un privilegio aislado, empaquetado en medidas paliativas que no contribuyen al bienestar general y que, en cambio, sí puede ser usado como instrumento de manipulación política (Álvarez Trujillo, 2011).

Los contratos estipulados en el artículo 355 de la Constitución, conocidos como contratos de interés público, tienen como finalidad la financiación de programas o proyectos de interés social, por parte del Estado, a particulares denominados organizaciones no gubernamentales para que colaboren con la realización de cometidos estatales.

La Ley 80 de 1993 y sus reformas, contenidas en la Ley 1150 del 2007 y 1474 del 2011, establecen las reglas aplicables a los contratos del Estado; sin embargo, a pesar de ese esfuerzo unificador, existen modalidades diferentes o exceptuadas (Valdivieso Valdivieso), entre ellas, la figura de los convenios de asociación de entidades privadas sin ánimo de lucro.

Como se advierte, el texto del artículo 355 de la Constitución contiene dos preceptos. Uno de ellos es prohibitivo y se constituye en regla general dirigida expresamente a

1 Constitución Política, Art. 355: "Ninguna de las ramas y órganos del poder público podrá decretar auxilios o donaciones a favor de personas naturales o jurídicas de derecho privado. El gobierno, en los niveles nacional, departamental, distrital y municipal podrá, con recursos de los respectivos presupuestos, celebrar contratos con entidades privadas sin ánimo de lucro y de reconocida idoneidad con el fin de impulsar programas y actividades de interés público acordes con el plan nacional y los planes seccionales de desarrollo. El Gobierno Nacional reglamentará la materia”. 
todas las ramas y órganos del poder público. En estas, el constituyente es claro en no dejar por fuera de esta prohibición a ningún ente de naturaleza pública del país, a los que se les prohibe expresamente decretar auxilios o donaciones en favor de personas naturales o jurídicas de derecho privado, utilizando una expresión inequívoca y clara para referirse a todos los particulares en general. El segundo precepto es facultativo, considera la excepción y la otorga específicamente al Gobierno, en los niveles nacional, departamental, distrital y municipal. A estos los autoriza o faculta para que celebren contratos con entidades privadas sin ánimo de lucro y de reconocida idoneidad (califica a los destinatarios de la actividad de fomento del Estado), para financiarlas con recursos públicos, en las condiciones y circunstancias especificadas en la norma constitucional y su reglamentación.

Al margen de esta reglamentación del artículo 355, resulta de importancia mencionar la Ley 489 de 1998 (Ley 489 de 1998), que reguló el ejercicio de la función administrativa, determinó la estructura y definió los principios y reglas básicas de la organización y funcionamiento de la administración pública, que, en su artículo 96, menciona expresamente los contratos de que trata el artículo 355 de la Constitución Política. Allí se les da el nombre de convenios de asociación con entidades privadas sin ánimo de lucro, término con el que se conoce ampliamente esta tipología y que preferimos en este trabajo, en lugar del de contrato de interés público, porque creemos que esta figura jurídica corresponde más a la naturaleza de un convenio de la administración que a las características de un contrato conmutativo, con contraprestaciones recíprocas y con intereses contrapuestos (García y Fino, 2014).

\section{Falencias en la aplicación de los convenios de asociación con entidades sin ánimo de lucro a la luz de los decretos 777 y 1403 de 1992}

Está claro que uno de los mecanismos de los que se vale el Estado para cumplir sus fines es la colaboración de los particulares en la gestión pública mediante los convenios de asociación con entidades privadas sin ánimo de lucro. El objeto de estos ha de ser el impulso de programas de interés público del ejecutor, acordes con los planes de desarrollo de la entidad pública, que requieren, para ejecutar o desarrollar dichos programas, que el objeto social de la entidad privada esté directamente relacionado con el objeto a contratar. A esto se suma la exigencia de contar con una reconocida 
idoneidad bajo parámetros que la misma normatividad establece como criterios para evaluar dicha condición sine qua non, lo que se constituye como requisito esencial contenido en el artículo 355 de la Constitución Política (Quiroz, 2014).

A los criterios anteriores, se suman las excepciones establecidas en los decretos reglamentarios 777 y 1403 de 1992, marco legal aplicable para la vigencia de los casos que se analizarán, con el objeto de evaluar las falencias en el uso de dicha figura jurídica. Aun así, a pesar de estos parámetros constitucionales y legales, el uso indebido de la figura jurídica y el consecuente desconocimiento de los principios de selección objetiva y transparencia contenidos en la Ley 80 de 1993, la Ley 1150 del 2007, la Ley 1474 del 2011 y decretos reglamentarios evidencian las falencias en la aplicación de los convenios de asociación. Desvían el cumplimiento del fin social y del interés común que se persigue, como se advierte con el estudio de los casos de procesos disciplinarios adelantados en la Personería de Bogotá, cuyo resultado fue la sanción disciplinaria de destitución con inhabilidades especiales desde los diez a los doce años en fallos de primera y segunda instancia.

A continuación se exponen las falencias evidenciadas en la aplicación de los convenios de asociación con entidades privadas sin ánimo de lucro durante la vigencia de los decretos reglamentarios 777 y 1403 de 1992

\section{Violación de los principios de transparencia y selección objetiva del Estatuto General de la Contratación Pública}

Para aplicar el artículo 355 de la Constitución política, figura de uso excepcional y restrictivo en materia negocial del Estado, es preciso que, al momento de estudiar la necesidad, la conveniencia y la justificación de la contratación, no solo se tengan presentes las disposiciones que consagra el artículo constitucional, sino también la verificación estricta y específica de cada una de las exclusiones contenidas en los decretos reglamentarios 777 y 1403 de 1992, que constituyen el régimen legal aplicable antes de la entrada en vigencia del Decreto 092 del 2017.

La falencia recurrente en el mal uso de la figura de los convenios de asociación fue la vulneración de los principios de trasparencia y selección objetiva, como consecuencia de la inobservancia de las exclusiones contenidas en el artículo $2 .^{\circ}$, numeral $1 .{ }^{\circ}$ del 
Decreto 777 de 1992 y el artículo 3. ${ }^{\circ}$ del Decreto 1403 de 1992 . Ello se traduce en que se celebraron convenios de asociación con entidades privadas sin ánimo de lucro para desarrollar actividades u obligaciones contractuales que implicaban contraprestación a favor de la entidad contratante. Esto quiere decir que no se impulsó el objeto social de la fundación acorde con el plan de desarrollo de las entidades públicas de que trata el artículo constitucional, sino que se ejecutaron de manera directa los proyectos a cargo del ente estatal, que debieron entonces celebrarse mediante las modalidades consagradas en el Estatuto General de la Contratación del Estado.

La vulneración de los principios de transparencia y selección objetiva de la contratación estatal se advierte en la medida en que lo que pretende la administración pública, al celebrar los convenios de asociación transgrediendo su régimen constitucional y legal, es obviar las modalidades que requieren la convocatoria pública con las exigencias y trámites establecidos en la normatividad aplicable.

\section{Desconocimiento de las excepciones previstas en los decretos reglamentarios 777 y 1403 de 1992}

El desconocimiento de las excepciones previstas en la reglamentación de la figura jurídica en estudio conduce indefectiblemente a la vulneración de los principios de trasparencia y selección objetiva consagrados en el Estatuto General de la Contratación Pública, en la medida en que se desarrollan objetos que no corresponden a la esencia del artículo 355 de la Constitución Política. Esta figura se concibió única y exclusivamente para impulsar programas acordes con los planes de desarrollo nacional, seccional y local. De esta manera, las entidades estatales, al momento de evaluar la procedencia de la celebración de convenios de asociación, debía analizar si el objeto y las actividades contractuales implicaban una contraprestación directa a favor de la entidad, caso en el cual tenía vedado usar esta figura constitucional, toda vez, que la contraprestación implicaba desarrollar actividades propias a cargo de la entidad y no las de la naturaleza social que correspondían al giro normal de las actividades de la ESAL. 
La contraprestación ${ }^{2}$ directa a favor del Estado implica la ejecución de un programa propio de la entidad estatal a cargo de ella, mientras que el convenio de asociación comporta un impulso del programa de la ESAL acorde con los planes de desarrollo nacional, seccional o local.

Por otra parte, la exclusión que contempla el Decreto 1403 de 1992 implica que no deben mediar instrucciones precisas por parte de la entidad contratante, por cuanto esta circunstancia evidencia la injerencia directa del ente estatal en el desarrollo contractual; es decir, como si se estuviera ejecutando el proyecto de la entidad desconociendo que la esencia del convenio de asociación es la actividad de fomento estatal. Esto equivale al impulso de los programas de interés social de la entidad privada sin ánimo de lucro, que gozará de plena autonomía e independencia en la forma de ejecutarlo.

\section{Falta de idoneidad para la ejecución del objeto contractual por parte de la entidad privada sin ánimo de lucro}

Los decretos reglamentarios 777 y 1403 de 1992 definieron la característica esencial para escoger la entidad sin ánimo de lucro, beneficiaria del impulso de la actividad de fomento por parte del Estado. Esta consistente en la reconocida idoneidad, definida como la experiencia con resultados satisfactorios que garantizarán su capacidad técnica y administrativa para realizar el objeto convenido, según evaluación a cargo de la entidad estatal que debe expresarse mediante escrito motivado.

"Reconocida idoneidad" es una expresión relacionada con un factor del sujeto o la persona jurídica sin ánimo de lucro, como son el reconocimiento, la acreditación ${ }^{3}$ y

2 La diferencia entre convenio y contrato radica en que el primero conduce a aunar esfuerzos frente a un objetivo común, mientras que el segundo alude al principio de conmutatividad, que implica acuerdo de voluntades con intereses opuestos; es decir, contraprestaciones entre las partes: una persigue la prestación de un servicio y la otra, pagar por él.

3 Significa, según el Diccionario de la Lengua Española (DLE), "acreditación 1. f. Acción y efecto de acreditar. 2. f. Documento que acredita la condición de una persona y su facultad para desempeñar determinada actividad o cargo". 
la trayectoria ${ }^{4}$, lo que no se compagina con los escasos seis meses de constitución de la ESAL que exigía el decreto reglamentario ${ }^{5}$.

En el desarrollo legal del artículo 355 de la Constitución política, la idoneidad se constituye como un requisito esencial del convenio de asociación. Es quizás el único criterio objetivo exigido para la escogencia de la entidad privada sin ánimo de lucro; de ahí que se define en relación con la experiencia basada en resultados satisfactorios que acrediten la capacidad técnica y administrativa de los ejecutores para realizar o desarrollar el objeto y las actividades del contrato.

\section{Subcontrataciones por parte de las ESAL}

Respecto de este falencia, es preciso señalar que tiene relación directa con el anterior punto tratado, en la medida en que, si bien es cierto, la normativa no contempla esta posibilidad, sino que la entidad sin ánimo de lucro ejecute directamente el objeto, esto supone que debe contar con la capacidad administrativa, técnica y financiera para que ello sea posible. Es así como la ausencia de criterios objetivos, al momento de la escogencia de la ESAL por parte de las entidades estales, conduce a que se contrate con entidades que no cumplen estos requisitos y que, por ende, tengan que subcontratar las actividades del objeto a desarrollar, con lo que se desnaturaliza la finalidad de esta clase de contratación.

Todo lo anterior causa el incumplimiento de lo dispuesto en la normativa, en el sentido de que, con los recursos públicos que recibía la entidad sin ánimo de lucro en razón del respectivo contrato, debían incurrir en gastos para cumplir exclusivamente su objeto.

4 Para el DLE, es "curso que, a lo largo del tiempo, sigue el comportamiento o el ser de una persona, de un grupo social o de una institución".

5 El término de seis meses de trayectoria de la ESAL fue lo que permitió la proliferación de fundaciones, corporaciones o asociaciones "de bolsillo", constituidas para determinado objeto y entidad pública, que ni siquiera contaban con la sede ni con la estructura organizacional, financiera, técnica y administrativa para ejecutar de manera idónea el objeto contractual, lo que generó el incumplimiento de las obligaciones y las subcontrataciones que estaban prohibidas en la reglamentación. 


\section{Inejecución o deficiente ejecución del objeto contractual}

Este aspecto se evidencia no solo en la ausencia de verificación de los requisitos que configuran la idoneidad de la entidad sin ánimo de lucro, sino también en la forma deliberada de obtener beneficio económico a través de las entidades fachada o de papel (Torres Carcamo, 2013) ${ }^{6}$; una vez celebrado el convenio de asociación, si bien puede certificarse a través de documentación su completa ejecución, ello no significa que se haya llevado a cabo de manera real y efectiva en beneficio de la población más vulnerable a la que estaba dirigido.

Asimismo, se presenta una baja o deficiente ejecución física de los convenios, como puede observarse de los resultados del informe de seguimiento a los convenios de asociación celebrados por las entidades y localidades distritales en la vigencia 2014, elaborado por la Veeduría Distrital, en el sentido de que, al analizar el avance al 31 de diciembre de esa anualidad, se encontró que de los 847 suscritos por el sector central del distrito, mediante el régimen especial por un monto de $\$ 338.949$ '790.117,149, 149 de ellos presentaron un adelanto en su ejecución de entre 0 y el $50 \%$, equivalente al 17,6\% del total, y 698 entre el 51 y el $100 \%$, que representó el 82,4\% restante. (Veeduría Distrital, 2014, p. 21)

Igual fenómeno revela el informe del ente distrital con lo ocurrido a escala de las localidades distritales. Según el avance al 31 de diciembre del 2014 en la ejecución de los convenios de asociación allí suscritos, con fundamento en el Decreto 777 de 1992 , por un monto de $\$ 59.771$ '211.185,221 de ellos presentaron un adelanto de entre 0 y el $50 \%$, equivalente al $75 \%$ del total, y entre el 51 y el $100 \%$, un total de 73 que representaron el 24,8\% restante (Veeduría, 2014, p. 56).

Esto se corresponde con el porcentaje de suscripción de los convenios en el primero y segundo semestres del 2014 , cuando el $40 \%$ correspondió al primero y el $60 \%$, al

6 Así se planteó en el artículo titulado "Los convenios como una burla desmedida a los principios del régimen de contratación estatal y al artículo 355 constitucional”, cuando en uno de sus apartes, señaló: “[...] Teniendo en cuenta que a través de los mal llamados convenios, como una forma de contratar con entidades privadas sin ánimo de lucro, que deben acreditar una reconocida idoneidad, que casi siempre es confeccionada por los adalid que manejan y estructuran los grandes despilfarros públicos, se le hace un desvío al régimen de contratación Estatal (sic), enriqueciendo de forma lícita a las mafias ancestrales y las que se crean coyunturalmente para apropiarse de la forma más fácil del dinero de todos los colombianos” (Metalemaestro, 2013). 
segundo de ellos, de lo que se infiere una deficiencia en la planeación contractual y en la ejecución presupuestal (Veeduría, 2014, p. 14).

\section{Deficiencia en la supervisión técnica, administrativa y financiera}

Frente a esta falencia, el Decreto 777 de 1992 dispuso en su artículo 6º que el control a la ejecución y el cumplimiento del objeto de dichos convenios se haría a través de la verificación por parte de la interventoría o la supervisión (Decreto 777 de 1992). Se contempló también la contratación directa con personas naturales o jurídicas especializadas y de reconocida idoneidad en la materia objeto del contrato para que ejercieran la interventoría, gastos que no podían exceder del $5 \%$ del valor del contrato al cual eran imputables.

Por otra parte, consagró que el contrato debía estipular las funciones que correspondieran al interventor, entre las cuales estaría la de exigir el cumplimiento del objeto del contrato y solicitar al contratista la información y los documentos que considerara necesarios en relación con su desarrollo.

Ahora bien, pese a que se contemplaron ese control y las responsabilidades de quien lo ejerce, en la práctica no se ejecutó de manera efectiva, oportuna ni eficaz, y en muchos de los casos estuvo ausente. Esto se reflejó en la certificación del cumplimiento total de las obligaciones sin la verificación previa de la ejecución técnica, administrativa y financiera. Esta situación contribuyó a que la inversión de los recursos no llegara a la población beneficiaria ni existiera un control en la ejecución de los dineros públicos que debía administrar la ESAL y, con ello, un creciente y desmesurado despilfarro del erario estatal ${ }^{7}$.

Adicionalmente, la norma reglamentaria consagró que el control de ejecución y cumplimiento podría ejercerse mediante interventores designados por la comunidad o por asociaciones cívicas, profesionales, comunitarias o juveniles. Esta disposición

7 Al respecto, en la publicación sobre el análisis de lo que ha sido la aplicación de la figura jurídica de los convenios de asociación en vigencia del Decreto 777 de 1992, se expuso: "[...] Grandes recursos económicos que bien pudiesen ser invertidos en planes sociales, se desaparecen de forma inmisericorde, a través de esta figura de generación de obligaciones económicas, afectando la sostenibilidad fiscal del Estado, al truncarse la posibilidad de inversión social, como la generación de empleo" (Metalemaestro, 2013). 
no tuvo, sin embargo, aplicación ni eco en la comunidad, dado que no se previó la manera de hacer efectiva dicha prerrogativa y porque al Estado no le interesó incentivar la participación ni el control de la ciudadanía, en razón de la práctica corrupta en la aplicación de la figura.

\section{Ineficiencia del gasto público de inversión social}

La finalidad de la contratación estatal tiene como fundamento el cumplimiento de los fines del estado, lo que se traduce en el servicio a la comunidad en pro del interés general. Uno de los mecanismos es la actividad de fomento a través de impulsar los programas y actividades de interés público de las ESAL, lo que implica optimizar o maximizar los resultados con el menor costo; es decir, el mayor número de beneficiarios con la inversión racional, eficiente y eficaz del presupuesto destinado para el efecto.

Lo anterior solo puede lograrse con un estudio financiero y económico serio que permita optimizar la inversión, medir el beneficio social, cuantificar los porcentajes de aporte estatal y del ejecutor y justificar la administración y la ejecución de los recursos estatales. Estas circunstancias no se encuentran establecidas a la luz de la reglamentación porque no previeron ejecutar una planeación, a cargo de las entidades públicas, que incluyera la elaboración de estudios técnicos, económicos y financieros para determinar o constatar el costo financiero de la propuesta o proyecto presentado o a cargo de la ESAL que se pretende impulsar. Esto se da porque, como se ha señalado, se consagró el criterio de reconocida idoneidad y contar con el certificado de disponibilidad presupuestal para respaldar el compromiso:

Antes de la celebración de los contratos, se deberá expedir un "certificado de Disponibilidad Presupuestal" suscrito por el Jefe de Presupuesto o quien haga sus veces en el organismo o entidad contratante, en el cual conste que dichos compromisos están amparados con apropiación presupuestal disponible. (Decreto 777 de 1992)

\section{Concentración en la contratación de un número reducido de ESAL que monopolizan la inversión estatal}

La figura de los convenios de asociación con entidades sin ánimo de lucro, al ser una forma especial de contratación a la que se le fijaron unas restricciones para usarla, 
se convirtió, junto con la contratación directa, en la regla general para las entidades estatales, a fin de ejecutar el presupuesto destinado a la contratación. No obstante, además de esto, la falta de criterios objetivos en la reglamentación para escoger la entidad sin ánimo de lucro abre un amplio margen de discrecionalidad a la entidad estatal que lleva a concentrar la contratación o a reducirla a ciertas entidades sin ánimo de lucro.

Así lo muestra el informe de veeduría realizado a la contratación para la vigencia 2014; en él, las entidades de orden distrital, tanto del nivel central como de las localidades, no solo ejecutaron la mayor parte del presupuesto para la contratación a través de esta figura jurídica, sino que lo hicieron con cierto número de $\mathrm{ESAL}^{8}$.

Se desdibuja así el sentir del Estatuto General de la Contratación Pública, que señala la licitación pública como regla general para escoger o seleccionar contratistas, lo que conduce a la convocatoria general de los actores del mercado, a los particulares que con previa determinación de requisitos puedan presentar en igualdad de condiciones una propuesta para contratar con el Estado, bajo claros conceptos de libre y sana competencia. La excepción es precisamente la contratación directa cuya aplicación, según los resultados de los estudios del 2014 por la Veeduría, supera el uso de la regla general.

\section{Falta de control jurídico y tributario de los dineros estatales entregados a las ESAL}

Bien es sabido que las ESAL, por su condición especial y su misión u objeto social encaminados al servicio a la comunidad, gozan de un especial régimen tributario que les da amplios beneficios porque se las considera como una extensión del Estado.

Con la Ley 1819 del 2016, aprobada en diciembre, la nueva reforma tributaria señaló un plazo de tres meses (primer trimestre del 2017) para que las ESAL existentes se adecuaran a la nueva normatividad tributaria, so pena de darles el tratamiento de sociedad comercial; es decir, quedarían sujetas a todas las cargas del Estatuto Tributario, como, por ejemplo, declarar renta sobre los excedentes (Salazar, 2017).

8 En el 2014, las entidades distritales suscribieron 847 convenios de asociación con entidades privadas sin ánimo de lucro por valor de \$338949790 117. Esto representó el 1,52\% del número y el 5,48\% del costo total de contratos de la administración distrital, sin incluir las alcaldías locales. Se firmaron en el mismo período 55517 por un monto de 6174601,0 billones de pesos, sumados los rubros de funcionamiento e inversión. 
Señala el artículo de la revista Mprende (Salazar, 2017) que, de acuerdo con las manifestaciones del gobierno y otros actores, en el ámbito de las ESAL se han incluido entidades que se valen de esa categoría para evadir impuestos en la medida en que simulen u oculten verdaderas actividades comerciales o de lucro. Esto abrió la necesidad de filtrarlas para que solo quedaran en ese régimen especial las que sí desarrollan actividades en beneficio para la comunidad.

Según datos de la Dian, existen más de 71000 esAL en Colombia, de las cuales el $77 \%$ (54933) se encuentran en el régimen tributario especial, mientras que el $23 \%$ (16729) no son contribuyentes ${ }^{9}$; por ello resulta importante esta nueva legislación tributaria que pretende contribuir con su control jurídico y tributario.

Por otra parte, el $48 \%$ de las entidades (33069) cuentan con actividades económicas no clasificadas, lo que permite que las ESAL tengan objetos sociales muy generales que abarcan toda clase de sectores y actividades. Esta ventaja junto con la tributaria hicieron que las sociedades con ánimo de lucro compitieran en condiciones de desventaja (Comisión de Expertos para Equidad y Competitividad, 2015)

\section{Dificultad o imposibilidad de medir el beneficio social en la actividad de las ESAL para determinar la racionalidad del gasto público de inversión social}

No existe una metodología estandarizada o generalizada que permita medir cuantitativamente el beneficio social de las actividades de interés público que realizan las ESAL con los aportes estatales porque este factor social debe contar con mecanismos para cuantificar factores de sensibilidad social, satisfacción, motivación y estímulo. Desafortunadamente, estos no pueden valorarse a través de la contabilidad financiera o económica de que se valen las sociedades comerciales para cuantificar el excedente o ganancias en sus operaciones.

9 Datos extraídos del informe final presentado al Ministro de Hacienda y Crédito Público, por parte de la Comisión de expertos para la equidad y la competitividad tributaria (Bonilla et al., 2015). 
Ante esta dificultad, solo pueden verificarse la rentabilidad de la actividad de fomento del Estado con el costo de la inversión dividido por el número de beneficiarios, a fin de determinar si la inversión se compensa con el beneficio directo del servicio prestado o si, por el contrario, el monto del presupuesto de inversión social destinado a las contrataciones con entidades sin ánimo de lucro no resulta proporcional al beneficio que presta a los sectores desprotegidos. En contraste, sumas exageradas se pierden en actividades etéreas y que ni siquiera son registradas o probadas por los ejecutores, pero que son pagadas por las entidades contratantes que ejercen una interventoría o supervisión pasiva e indiferente frente al despilfarro de los recursos públicos.

Adolfo Rodríguez Martínez, profesor de contabilidad y finanzas de la Universidad de Zaragoza, señala:

Tras reflexionar sobre los objetivos y usuarios de la información financiera en el ámbito no lucrativo y sobre los estados financieros que aportan dicha información, se propone la utilización de indicadores que evalúen los factores clave de eficiencia de la entidad, su viabilidad, el grado de cumplimiento de los fines fundacionales, la eficiencia gestora y el coste de los servicios prestados (Rodríguez Martínez, 2005).

El tema de la medición de beneficios sociales fue objeto de estudio y análisis de la profesora del Departamento de Economía y Empresa de la Universidad de las Islas Baleares, María Antonia Ribas Bonet (2001). Ella señala la necesidad de elaborar el balance social de las entidades no lucrativas, lo que ayudaría a incorporar transparencia en la gestión y actividades de la organización a través de estandarizar un modelo que permita ejercer un control eficaz de las actividades de dichas entidades y de los recursos provenientes del Estado que sirven a la actividad de fomento. Empero, advierte en su trabajo investigativo sobre la complejidad de abordar esta herramienta, dados los factores subjetivos que surgen y la dificultad en cuantificarlos o hacerlos medibles para obtener resultados que redunden en beneficio de la misma entidad y, por supuesto, de los beneficiarios de su actividad en beneficio de la comunidad (Ribas Bonet M. , 2001).

En Colombia, desafortunadamente el uso de la figura de los convenios de asociación, en la percepción general de la ciudadanía, está asociado a actos de corrupción debido a escándalos como los de los casos de comedores comunitarios para la población infantil, la desnutrición de la niñez indígena en La Guajira o el carrusel de contratación en la 
ciudad capital. En ellos están involucradas o vinculadas fundaciones y corporaciones que desviaron los fondos públicos en detrimento del beneficio social de los sectores a los que iban dirigidos.

Las anteriores falencias se evidenciaron a través del estudio de cinco casos disciplinarios conocidos y fallados en primera y segunda instancia por la Personería de Bogotá, donde de manera clara y recurrente aparecen los presupuestos fácticos que evidencian los problemas y deficiencias en la aplicación de la figura de los convenios de asociación durante la vigencia de los decretos reglamentarios 777 y 1403 de 1992.

El criterio de escogencia de los casos para estudio fue, en primer lugar, el impacto económico y social, reflejados en una ineficiente ejecución del objeto propuesto y la ineficacia en la inversión social de los recursos estatales, si se tiene en cuenta que los proyectos estaban orientados a satisfacer necesidades de población vulnerable, como mujeres víctimas de violencia y comederos comunitarios, así como proyectos de interés público orientados a la recuperación del medio ambiente local y programas para fomentar e incentivar la actividad comercial en la localidad (Sarmiento, Medina y Plazas, 2017).

Los procesos disciplinarios corresponden a las radicaciones asignadas por la Personería de Bogotá, D. C., con los números 21335-2009, 7509-2011, 19657-2012, 2170 2014 y $31189-2014$.

\section{LA INCLUSIÓN DE LOS CONVENIOS DE ASOCIACIÓN COMO QUINTA MODALIDAD DE LA CONTRATACIÓN ESTATAL PARA GARANTIZAR LA APLICACIÓN DE LOS PRINCIPIOS DE TRANSPARENCIA Y SELECCIÓN OBJETIVA}

La propuesta de incluir un proceso contractual para la tipología propia de los denominados convenios de asociación con entidades privadas sin ánimo de lucro, como una quinta modalidad de selección, obedeció en primera instancia a la falta de armonización de esta clase de contratos consagrados constitucionalmente con el Estatuto General de la Contratación Estatal, que durante más de 26 años permaneció con un régimen propio y ajeno a la normatividad contractual del Estado. En segundo 
lugar, porque la nueva y actual reglamentación no fijó criterios claros ni objetivos para escoger la ESAL más favorable al cumplimiento cabal, eficaz y eficiente de la actividad de fomento del Estado, a pesar del avance significativo que representó consagrar la aplicación de los principios de la contratación estatal en esta clase de contratos, así como la remisión a las normas generales contractuales ante los vacíos que contenga la reglamentación de la figura. Por otra parte, tampoco se concibió la inclusión de esta tipología contractual como una quinta modalidad de selección en el Estatuto General de Contratación Estatal. En razón de la naturaleza misma de los actores particulares que aquí intervienen, ella merece un modo particular, específico y propio que permita, dentro de una sana competencia, obtener el máximo beneficio público con una óptima racionalización del gasto y una satisfacción social basada en la participación efectiva del control ciudadano. Ello precisa de la aplicación de los principios de transparencia y selección objetiva, con lo cual se cierra la puerta a que se continúe con el uso indebido de la figura jurídica (Blanco, 2015).

\section{Conclusiones}

$\mathrm{Al}$ analizar cinco procesos disciplinarios adelantados por la Personería de Bogotá por la indebida aplicación de la figura jurídica de los convenios de asociación con entidades privadas sin ánimo de lucro, durante la vigencia de los decretos reglamentarios 777 y 1403 de 1992, se constató que el uso indebido de esta tipología obedeció a la violación de los principios de transparencia y selección objetiva previstos en el Estatuto General de la Contratación Pública. Se obviaron así las modalidades propias del régimen contractual por desconocimiento de las exclusiones contempladas en la reglamentación, lo que se presentó como una constante en los casos escogidos para demostrar que existen falencias en la aplicación de la normativa citada.

Por otra parte y subsumidos en este ámbito, se presentó falta de idoneidad para ejecutar el objeto contractual por parte de la entidad privada sin ánimo de lucro, circunstancia que no solo proviene de la falta de verificación, por parte de la entidad pública, del elemento característico de idoneidad requerido a las entidades ejecutoras, sino por la deficiencia normativa que establece un término mínimo de existencia de seis meses. Este lapso resultaba insuficiente para que se pudiera contar con la trayectoria que comportaba el requisito de idoneidad que exigía una experiencia con 
resultados satisfactorios que garantizara la capacidad técnica y administrativa para realizar el objeto convenido.

En consecuencia, esta deficiencia propició que las ESAL subcontrataran los bienes y servicios que debían proveer desnaturalizando la finalidad de esta clase de contratación. En primer lugar, porque el propósito del fomento va dirigido a impulsar la actividad misional de las ESAL, lo que se traduce en su indiscutible capacidad para desarrollar todos los componentes necesarios para cumplir a cabalidad el objeto contractual. En segundo lugar, porque al requerir los servicios de un tercero como ejecutor se disminuye la eficacia del recurso público invertido, por cuanto la financiación del Estado no cumplía en el $100 \%$ con el beneficio social proyectado.

La inejecución o deficiente ejecución del objeto contractual evidenció un alto grado de corrupción, por cuanto la inversión social no beneficiaba a los destinatarios de los programas y se convertía en una forma de favorecimiento económico a entidades fachada o de papel.

Otras deficiencias producto de la práctica de contratación directa de las ESAL, sin criterios objetivos, que desviaron la finalidad de esta tipología se concretan en la deficiente actividad de supervisión técnica, administrativa y financiera, dado que no se previó la manera de hacer efectiva dicha prerrogativa y porque al Estado no le interesó incentivar la participación y el control de la ciudadanía, en razón de la práctica corrupta en la aplicación de la figura. Del mismo modo, la ineficiencia del gasto público de inversión social se presenta por ausencia de un estudio financiero y económico serio que permita optimizar la inversión traducida en la maximización de los resultados con el menor costo, la medición del beneficio social y la cuantificación de los porcentajes de aporte estatal y del ejecutor, así como la justificación de la administración y la ejecución de los recursos estatales.

La falta de unos criterios objetivos en la reglamentación para escoger la entidad sin ánimo de lucro permitió un amplio margen de discrecionalidad por parte de las entidades estatales, lo que conllevó a concentrar la contratación o a reducirla a ciertas entidades sin ánimo de lucro.

Adicionalmente, se presenta la dificultad o imposibilidad de medir el beneficio social en la actividad de las ESAL para determinar la racionalidad del gasto público 
de inversión social, dado que no existen mecanismos o sistemas de medición que cuantifiquen factores como la sensibilidad social y la satisfacción y el impacto que generen el desarrollo y ejecución de los proyectos por medio de los cuales se impulsa el sector sin ánimo de lucro, que no han sido abordados por el Gobierno nacional a través de ninguna de las reglamentaciones expedidas para esta tipología de convenios.

Todo lo anterior mostró que los convenios de asociación con entidades privadas sin ánimo de lucro no podían seguir siendo ajenos al estatuto contractual; de ahí surge la necesidad de incluirlos como una modalidad autónoma e independiente, con unas reglas que respondan a su naturaleza y garanticen los principios de transparencia, selección objetiva y cumplimiento de los fines de interés social, con la participación efectiva de la sociedad para que ejerza su control y vigilancia.

\section{REFERENCIAS}

Acto Legislativo 1 de 1945. (17 de febrero de 1945). Por el cual se confieren algunas atribuciones al director de la policía. Bogotá: Diario Oficial Año LXXX n.․ 25769.

Acto Legislativo 1 de 1968. (17 de diciembre de 1968). Por la cual se reforma la Constitución Política. Bogotá: Diario Oficial Año CV No. 32673.

Álvarez Trujillo, A. (Enero a junio del 2011). Donaciones y subsidios en la Carta política de 1991. Revista CES Derecho, 2(1).

Barragán, D. (2016). La construcción de la mentalidad democrática como necesidad en el posconflicto. Via Inveniendi et Iudicandi, 11(1), 37-57.

Blanco, C. y Gómez, D. (2016). Constitución política e integración andina desde las nociones de soberanía y democracia en Perspectivas críticas del derecho constitucional colombiano. Bogotá: Universidad Libre

Blanco, C. (2015). La cláusula de renegociación en los contratos de concesión de obra pública. Revista Republicana, 19. Recuperado de http://ojs.urepublicana.edu.co/index.php/ revistarepublicana/article/view/254

Blanco, C. (2013). Aproximación a la noción de soberanía estatal en el marco del proceso andino de integración. Revista Republicana, 15. Recuperado de http://ojs.urepublicana. edu.co/index.php/revistarepublicana/article/view/23 
Bonilla, R., Córdoba, R., Lewin, A., Morales, O. A., Montoya, S., Perry, G., Piza, J. L., Urrutia, M., Villar, L. et al. (2015). Comisión de expertos para la equidad y la competitividad tributaria. Informe final presentado al ministro de hacienda y crédito público. Bogotá: Fedesarrollo. Recuperado de https://www.fedesarrollo.org.co/sites/default/files/ LIBAgosto2016Comision.pdf

Comisión de Expertos para la Equidad y la Competit. (2016). Informe Final presentado al Ministro de Hacienda y Crédito Público. Bogotá, D. C.: La Imprenta Editores.

Corte Constitucional (1994). Sentencia C-372. [M. P. V. Naranjo].

Cortés, S. (enero-junio del 2016). Derechos humanos en las políticas de paz y posconflicto en Colombia. Via Inveniendi et Iudicandi, 11(1), 129-145. Recuperado de http://revistas. usantotomas.edu.co/index.php/viei/article/view/2926/2798

Cortés, S. (2013). La globalización económica y los derechos humanos. Revista Via Inveniendi et Iudicandi, 8(2), 56-78.

Decreto 777 de 1992. (18 de mayo de 1992). Por el cual se reglamenta la celebración de los contratos a que se refiere el inciso segundo del Artículo 355 de la Constitución Política. Bogotá: Diario Oficial Año CXXVIII No. 40451.

Gallego, J. (enero-junio del 2014). Paradoja y complejidad de los derechos humanos en la sociedad moderna. Sentido y comunicación. Revista Iusta, 40, 143-165.

García, M. y Fino, G. (julio-diciembre del 2014). Los impuestos territoriales en Colombia y la inequidad social: ¿la voluntad de la clase dominante erigida en ley? Revista Iusta, 41, 6175. Recuperado de http://revistas.usta.edu.co/index.php/iusta/article/view/2471/2408

Garzón, E. (2013). Globalización del derecho, fetichismo legal el velo de los derechos humanos. Revista Verba Iuris, 30, 34-78.

González, O. (2014). La Corte Constitucional como agente del campo jurídico colombiano: la omisión legislativa de principios constitucionales. Revista Iusta 41(2), 123-137.

Guarín, E. A. y Aldana, J. (2016). Estado jurisdiccional y bien común. Revista Verba Iuris, $11(36), 13-26$.

Henao Hidrón, J. (1992). Panorama del derecho constitucional colombiano (8. ${ }^{a}$ ed.). Bogotá: Temis. 
Humbarita, J. (2015). Derecho constitucional hispanoamericano frente a la realidad institucional: manifiesta divergencia. Revista Iusta, 43(2), 45-68

Jiménez, W. G. y Soler Pedroza, I. (2013). Manual para el estudio y análisis de politicas públicas y la gobernabilidad. Bogotá: Ibáñez.

Ley 489 de 1998. (30 de diciembre de 1998). Por la cual se dictan normas sobre la organización y funcionamiento de las entidades del orden nacional, se expiden las disposiciones, principios y reglas generales para el ejercicio de las atribuciones previstas en los numerales 15 y 16 del artículo 189 . Bogotá: Diario Oficial n. ${ }^{\circ} 43.464$.

Metalemaestro. (2013). Los convenios como una burla desmedida a los principios del régimen de contratación estatal y al artículo 355 constitucional. Recuperado de http:// www.metalemaestro.com/index.php/noticias-de-interes/opinion/789-los-convenioscomo-una-burla-desmedida-a-los-principios-del-regimen-de-contratacion-estatal-y-alarticulo-355-constitucional

Millán, J., Blanco, C. y Guecha, C. (2017). Los procesos de selección de operadores privados del servicio público de televisión en torno a la libre concurrencia. En Libro Justicia Constitucional. (Tomo 2). (pp. 199- 221). Recuperado de https://repository.usta.edu.co/ handle/11634/4249

Palomares, J. y Calonje, N. (2015). Tratados de libre comercio Colombia-Asia: cuestión preliminar y perfiles de negociación. Revista Iusta, 43(1), 17-41.

Pardo, N. (2014). Un recorrido por los derechos colectivos en la jurisprudencia argentina. Via Inveniendi et Iudicandi, 9(1), 32-49. Recuperado de http://revistas.usantotomas. edu.co/index.php/viei/article/view/1338/1540

Patarroyo, S. y Benavides, P. (2014). Rupturas asignificantes: revisiones críticas en torno al derecho. Via Inveniendi et Iudicandi, 9(1), 7-31.

Quiroz, M. (2014). Acercamiento a las “oposiciones paradigmáticas" entre neoconstitucionalismo y positivismo jurídico. Revista Iusta, 41(2), 77-97.

Ribas Bonet, M. A. (2001). El balance social como instrumento para la evaluación de la acción social en las entidades no lucrativas. Ciriec, revista de economía. Recuperado de http://www.redalyc.org/pdf/174/17403907.pdf 
Rodríguez, E. (2016). El pasaje del estado y el derecho a la postmodernidad en Revista Via Inveniendi et Iudicandi, 11(2) 11-37.

Rodríguez, A. (2005). El análisis económico-financiero de las entidades no lucrativas. Indicadores de Gestión. Acciones e Investigaciones Sociales, pp. 9-112. Recuperado de https:// dialnet.unirioja.es/descarga/articulo/1185131.pdf

Saidiza, H. y Carvajal, J. (2016). Crisis del Estado de derecho en Colombia: un análisis desde la perspectiva de la legislación penal. Revista Iusta, 44(1), 17-39.

Salazar, J. C. (2017). Las entidades sin ánimo de lucro deberán adecuarse a la reforma tributario”. Mprende. Recuperado de http://mprende.co/impacto-social/las-organizacionessin-\%C3\%A1nimo-de-lucro-debenadecuarse-la-reforma-tributaria

Sänger, R. (2015). La garantía de la propiedad y el principio de proporcionalidad como límites de la carga tributaria en Alemania. Revista Iusta, 42(1), 73-99.

Sarmiento, D., Medina, S., y Plazas, R. (julio-diciembre del 2017). Sobre la responsabilidad y su relación con el daño y los perjuicios. Revista Via inveniendi et Iudicandi 12(2), 101 115. doi: http://dx.doi.org/10.15332/s1909-0528.2017.0002.04

Tirado, M., Bedoya, J. y Blanco, A. (2016). Bioética y transhumanidad: hacia una aproximación al consumo de sustancias nootrópicas en el campo académico. Bioética y Docencia. 91.119 Recuperado de https://repository.usta.edu.co/handle/11634/1527

Valdivieso Valdivieso, W. O. (s. f.). Contratos con entidades sin ánimo de lucro, previstos en el artículo 355 de la Constitución Política de 1991. Un estudio sobre las modalidades abusivas.

Veeduría Distrital. (2014). Seguimiento a los convenios de asociación, celebrados por las entidades y localidades distritales, en la vigencia 2014, con fundamento en los decretos 777 y 1403 de 1992 y 2459 de 1993. Bogotá. 